\title{
Non Profit Product Placement: Human Rights Advocacy in Film and Television
}

\author{
Carla Winston, University of British Columbia \\ (draft-not for attribution without permission)
}

Amnesty International is one of the world's oldest and best-known human rights advocacy organizations. Founded in 1961, it has a history of working towards human rights for all by using both government pressure and grassroots education to get its messages out. It operates via a network of incountry researchers and activists, national sections which pressure their own governments, and international secretariat which coordinates efforts and works with international institutions. It is also a membership-based organization: AI boasts over 7 million members, supporters and activists in over 70 national sections (Amnesty International 2014). As generations change, however, AI is in danger of losing both its popular appeal and its political power in the face of competition from other organizations and an increasingly graying membership base. As then-AIUSA spokesperson Dennis Palmieri explained in 2002, 'We need to get our message out to people who are not doctoral students (Calvo 2002).' But how to do it?

Although an increasing number of non-governmental organizations (NGOs) are making forays into cultural marketing, Amnesty International's US section (AIUSA) stands out as particularly active in the field of human rights and culture. It has sponsored concert series, held film festivals, enlisted celebrity spokespeople, created teaching guides for popular films, sold specially commissioned music albums, and more. Amnesty's overall work with the artistic community suggests three interconnected goals: To educate and spur action on specific human rights issues, to increase youth membership, and to contribute to building a 'culture of human rights.' The collective desire for entertainment, the power of the arts to teach and influence viewers, and the popularity of the cultural elite offer a different way to make political issues interesting: by making them 'cool,' 'normal,' and possibly both.

One of the less well-known aspects of AIUSA's (and other NGOs') cultural marketing efforts is the use of embedded advertising in popular film and television. This article argues that by engaging in 
product placement, or the placement of AI's logo, image, and issues within popular fictional films and television shows, it is trying to 'sell itself' as both an organization and as a cause. Amnesty itself may be thought of as a brand, but its 'product,' instead of being a consumer item such as shoes or computers, is human rights activism. However, unlike other forms of cultural engagement, product placement uses an inherently fictional creation to advance real-world goals. This intersection of fiction, entertainment, outreach, and very serious real-world issues presents both opportunities and challenges, risking trivialization of the issues and people at hand at the same time as it heralds the possibility of engaging new supporters. It also leads to new ethical dilemmas beyond the concerns related to the increasing corporatization of non-profit work.

This article will analyze the rationale for such efforts, explain the process and typology of product placement, provide some illustrative examples, and discuss a few of its ethical implications when applied to political or non-profit activism. Using discursive and visual analysis of films and television shows, the author will examine how different types of product placement serve to create brand and issue recognition for Amnesty International and, perhaps, norms of political engagement with global human rights issues. In doing so, it offers an alternative frame through which to understand the increasingly corporatized nature of modern political advocacy: rather than harming the activist landscape by de-radicalizing political engagement, pushing for a 'human rights culture' seeks to do exactly the opposite: to normalize human rights activism as a facet of everyday life.

\section{POLITICS ON SCREEN}

The intersection of fiction and real-world politics is not well studied within political science. Whereas studies abound of politics and activism with respect to the news media (Ramos, Ron et al. 2007, Vestergaard 2008, Krain 2012), relatively little has been written about the way in which non-documentary media affect our perceptions of what politics, political behavior, or political advocacy is or should be. 
Cinema and media studies have long recognized that the way life, including political life, is presented on screen affects how viewers understand it (van Zoonen 2007).

A limited number of studies have suggested that television and film about politics can indeed have an effect on how viewers respond to politics in general (Holbert, O. et al. 2003). This is possible because television and film cut across the multiple ways that people process politics: media discourse, experiential knowledge and popular wisdom. 'Media discourse' here means the spread of politics, and political topics, beyond its traditional home of news and documentary media. The 'popular wisdom' portion of this equation is the general sense of the world shared by both the fiction and the viewer's sense of the real world. The care taken to make films and television seem like real life - using multiple consultants, language or movement coaches, filming locations, set decoration choices, even employing former speechwriters as screenwriters - enhances our belief that what is on the screen is reflective of the real world, even if the exact circumstances are different (van Zoonen 2007, 58). Lastly, 'Experiential knowledge' results from the familiarity with characters and emotional investment that people make in following a story or television show. This connection - the feeling that we 'know' a character - makes their experiences and opinions more important to us than persons met only fleetingly.

Given these three forms of gaining and interpreting political knowledge, I suggest that it may be possible for organizations and norm entrepreneurs to make use of both symbolic and information politics (Keck, Sikkink 1998) by inserting real-world issues and information into fictional constructs (also known as 'edutainment'). ${ }^{2}$ If a film or TV show incorporates a real-life issue or situation into its storyline, the dramatized version of reality will still be in some way 'true to life.' Information can be presented that the audience may not have known before, be framed in such a way as to make it emotionally compelling for the viewer, and potentially offer solutions via individual action. This process, although occurring in a fictional universe, is the same thing that Amnesty International has attempted to do for decades by telling the stories of individuals affected by and fighting for human rights, and providing members the opportunity to become human rights defenders themselves. 


\section{PRODUCT PLACEMENT: BRAND MANAGEMENT AND NORMATIVE CHANGE}

Product placement, or the strategic placement of an organization's name, logo or products within

a fictional world, is a well-known and often very successful form of corporate marketing. ${ }^{4}$ Also known as embedded advertising, it has been employed for over 50 years, with increasing frequency and variety of format: one study calculated that the television audience sees, on average, one product placement every three minutes of programming (La Ferle, Edwards 2006). It is used by filmmakers to reflect a world in which corporations and products actually exist, but it is also used strategically by corporations to build brand and product knowledge, to enhance image or popularity, or to "normalize" products or the actions which might require them. ${ }^{5}$ I argue that in seeking organizational visibility, AIUSA and other NGOs act much like a corporation seeking consumers.

'Amnesty International' is a brand. It was one of the first human rights groups to use image branding, through its distinctive candle-in-barbed-wire logo (Cmiel 1999). Just like Nike or Apple, which each have distinctive identities and logos to match, people associate Amnesty with a certain type of 'product' - grassroots human rights education and activism. However, trust in Amnesty's 'brand' is higher than trust in most corporations at least partially because it is not like a corporation: 'profits are not a goal; altruism and goodwill rule (Dauvergne, LeBaron 2014).'

Therefore, associating human rights with 'Amnesty International' via a branding or outreach campaign makes someone interested in human rights more likely to visit the website, join a group, or take an Amnesty-directed political action than if they do not associate the product with an organization at all. It is also likely to lead to more funding for Amnesty through membership dues, grants from foundations, and other sources of income which make decisions based on trust in organizational partners. At the very least, simple product placement should lead to increased visibility for the organization itself: Amnesty International will become better recognized as a leading human rights advocacy group. 
Second, depending on the context in which it is placed, it is possible to make a product 'cool.' Take, for example, James Bond and the Aston Martin (Cooper, Schembri et al. 2010). This makes the product, and the organization promoting it, more likely to be chosen over a competing brand. If someone associates both Human Rights Watch (HRW) and Amnesty International with human rights, but one is perceived as 'cooler' than the other, all other things being equal that person is more likely to direct their attention to the 'cooler' organization, giving Amnesty a distinct advantage over its peers in recruiting and funding. If the opposite, Human Rights Watch receives the benefits. ${ }^{6}$

Some types of placements may lead to results beyond a perception of trendiness. One particular goal, for $\mathrm{AI}$ and for those who engage in principled action, is to create affect: an emotional connection with the issues presented that drives action in a way that dry numbers or facts cannot (Slovic 2007). From viewing human-rights related stories and incorporating the informational and emotional cues available about both the issue and the types of people affected by it, viewers will probably learn at least something about the specific issue (the global arms trade, conflict diamonds) with which they are presented. They will also be able to link that information to the physical and emotional experience of those whose rights are being violated. If viewers become both educated and emotionally involved with an issue they feel they can positively impact through personal action, even on a part-time basis (be it political letter-writing, voting or consumer-based methods), that person is presumably more likely to do so than one who is educated on an issue but not emotionally impacted by it. The nature of storytelling and the framing of issues have the ability to make us want to act; perhaps that may be possible if we seek out the organization mentioned in the story itself.

Lastly, and also depending on placement, products may end up seen as 'normal.' This is the simplest expression of a norm cascade, whereby standards of appropriate behavior are adopted because key influential actors have already done so, and new norm adopters wish to emulate their behavior. Slowly, such attitudes and behavior are internalized, and the specific reasons for belief and practice cease to be actively contested (Finnemore, Sikkink 1998). On a general level, simple product placement in 
otherwise non-political film and television may 'normalize' or 'mainstream' human rights, whereas previously the average viewer may have relegated them to a separate sphere of 'political' activity. This is the essence of the 'human rights culture' AI is trying to build: a more sustained involvement in human rights activism in general, beyond issue-related or 'trendy' political action.

\section{How does it work?}

In controlling where and how an organization such as Amnesty is portrayed in fictional entertainment, I argue that each product placement decision becomes an act of strategic communication. Placements can be refused if the content of the entertainment does not fit Amnesty's desired image, but they can also be solicited in pieces which appeal to the audiences that it would like to reach. This section details the process of securing and agreeing to placements, as well as its forms and intended effects.

The actual placement of a name, logo or product can occur via three pathways. First, if writers, costumers or set designers, or even actors, desire to use Amnesty International's name or products (tshirts, posters, mugs, etc.) in a for-profit production, they must ask Amnesty for permission to use its copyrighted materials. Second, AIUSA receives volunteered services from a company called Hero Entertainment Marketing to push for the inclusion of Amnesty products where someone on the production has not specifically asked for it already. Hero performs the same services for regular companies such as LEGO, Cuisinart and, the Financial Times (Hero Entertainment Marketing nd). Third, and most like traditional information politics or advocacy efforts, Amnesty works with interested writers and producers in the film industry to create entertainment content that reflects human rights issues and values. In the first two types, because Amnesty does not pay for the placement (either directly or indirectly), the Federal Communications Commission (FCC) does not require that it be disclosed. In the third case, the fee for this consultancy can come in the form of a product placement or mention of the organization in the final product, or inclusion of experts on additional DVD materials, and must be made public. However, these 
sponsorship disclosure requirements are for television shows, and do not currently apply to films produced for theatrical release (Fujawa 2012).

There are two basic forms of product placement: simple visual \& auditory placements (referred to as product placement or prop placement) and featuring products heavily within a plot (product integration). Each has the potential to affect both recall and positive attitudes towards the product in question, although this potential varies depending on clarity, placement, timing and repetition, reaction, integration with character identity or character development, and other factors (Jones 2002).

Studies on representation and modality have shown a difference between visual and auditory delivery of signals. In a film and television context, the visual mode sets the tone and makes an environment feel realistic, while the auditory mode actually delivers the content - the story itself -- via the script. Therefore, seeing a candle-and-barbed-wire logo and hearing the words 'Amnesty International' will have different effects on both recall and preference. Whereas seeing the logo might set a scene, i.e. explain preferences or provide cues as to character development, hearing the words 'Amnesty International' might instead serve a specific character or plot arc, and in terms of advertising effectiveness would be considered 'more meaningful' than a mere visual cue (Jones 2002).

The second form, plot integration, is potentially the most meaningful form of placement. It incorporates the organization or product (in this case, human rights) directly and meaningfully into the storyline. If connection with the plot positively influences informational recall from films, it stands to reason that a film with "non-profit product" integration, and therefore concerned with issues relevant to Amnesty International, might generate interest in the group or at least a desire for further issue-related research.

The majority of placements in television are of the first kind, and are both fleeting and unobtrusive: they appear onscreen for generally fewer than 5 seconds and are either visual or verbal, but not usually both. Visual cues tend to be prominent and uncluttered, but in the background, and do not 
necessarily interact with characters or with plot. Auditory cues, on the other hand, tend to be spoken by a lead or supporting character and have direct significance as to their role in the scene (La Ferle, Edwards 2006). I suggest that they may effect efforts at brand management, but are unlikely to spur either greater subject knowledge emotional response to human rights issues in general.

However, for plot integration, questions of story and character are both potentially important to human rights organizations. What exactly is explained or discussed in a story, and in what terms, help frame discussions about whether issues are human rights-related or not in the first place. A fictional character can function in the same manner as a real-life representative of an issue or a normative perspective; by humanizing an abstract concept, readers or viewers may imagine themselves and their reactions to such a situation and their emotional responses may lead to greater attachment to the political issue or actor. ${ }^{8}$

It should be cautioned that the nature of the creative process makes the results of placements uncertain. Even if they manage to get into a script or onto a set (which depends on production staff choosing objects as set or costume pieces), several production or post-production processes (editing, camera angles, acting decisions, etc.) may intervene, resulting in a placement that disappears in production or is unintelligible to the viewer. Non-profits, unlike traditional companies which use product placement, are not providing funding for the creative process in return for the successful placement of their product. Their inclusion in the finished film or show is therefore dependent upon creative, rather than financial, decision-making processes, and therefore much less secure.

\section{THE CONTENT AND CONTEXT OF AI PRODUCT PLACEMENTS}

Many viewers of popular television and film have seen Amnesty International product placements, even if they were not aware of it at the time. Some of Amnesty International's representative 
placements will be examined below to help illustrate their expected effect on viewers' recognition of, and feelings about, AI as an organization (the 'brand') and human rights activism in general (the 'product').

\section{Visual: Set Dressing and Costume}

Visual placements could be part of a set or as a character's wardrobe. Considerations for the placement's effectiveness might include whether the place is public - a school or work hallway - or private, such as a character's home or office, as well as the relative prominence of the character wearing the logo. Also to be considered is the 'loudness' of the logo or item itself.

a) Set dressing

On the television series The West Wing, in the office of Toby Ziegler, White House Communications Director and a committed civil liberties advocate, hangs an Amnesty International poster (Lehmann 1999):

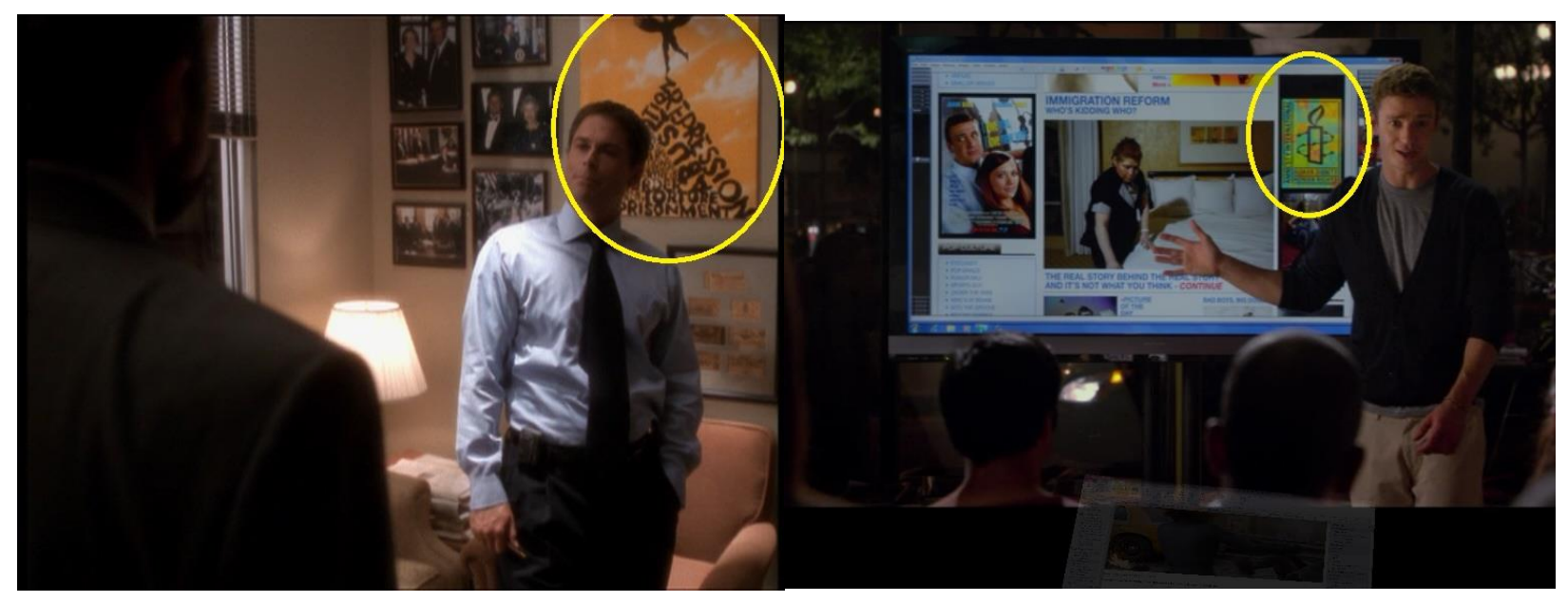

Figure 1 and 2: The West Wing (1999) and Friends with Benefits (2011)

It is a visually striking poster, in a bright color with contrasting text which includes human-rights related terms such as 'oppression,' 'torture,' and 'abuse.' It is designed to catch a viewer's eye. However, 
the poster is never quite seen in full: over the course of at least four seasons the words 'Amnesty International' are never actually seen onscreen. This is seemingly a problem for Amnesty, as the lack of name or logo recognition would negate any influence the poster might have. However, themes which might eventually lead a viewer to Amnesty International are easy to recall given the poster's 'loudness' and association with a specific character with human-rights-oriented politics.

A more directly informative placement occurs on a large screen in the office of a magazine in the film Friends with Benefits (Gluck 2011). Both the distinctive logo and the name 'Amnesty' are easily identified by the viewer. However, the poster appears only once in a two-hour film, rather than repeatedly over the course of multiple television episodes. This means that viewers have a smaller chance of noticing the poster in the first place. Recall may be more specific to Amnesty, but it is less likely to happen overall.

Both of these posters are seen in the offices and buildings of fictional politically aware figures (a Democratic White House and a progressive magazine office), and a viewer would not be particularly surprised to see such a poster in a politically liberal setting. ${ }^{9}$ Viewers who are interested in politically engaged forms of entertainment are both more likely to notice the poster and to agree with Amnesty's general positions. Thus the placement achieves brand recognition, but does not necessarily change viewers' beliefs about the 'normalcy' of human rights activism in politically neutral settings. If human rights NGOs wish to be viewed as non-partisan, they must broaden their visual messaging beyond partisan placements.

For example, there is a fleeting image of an Amnesty logo in The Avengers (Whedon 2012). 


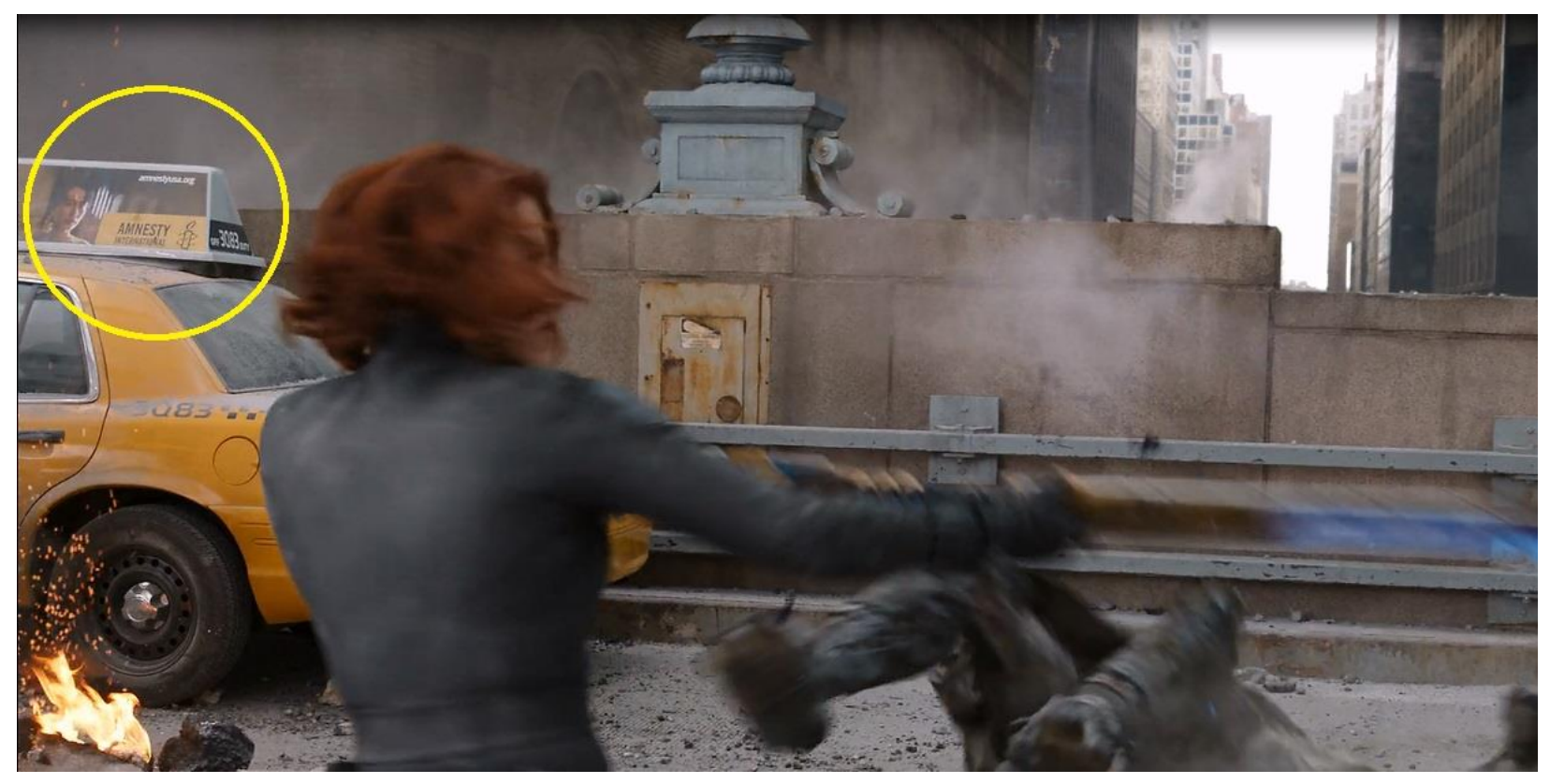

Figure 3: The Avengers (2012)

Set on top of a taxi in downtown Manhattan, the placement of this logo is not political at all and, like Friends with Benefits above, not even placed in the context of a politically engaged film. For any viewers who manage to catch this placement, human rights activism (and Amnesty International in particular) is portrayed as a normal part of everyday life. That is, if one is able to actually see the image, much less process it: the logo is visible for less than a second in the middle of an action sequence.

Another typical space without necessarily political connotations, especially for young viewers, is high school. The placement of Amnesty posters in high school hallways and classrooms shows the group as active in a non-political setting that is both highly recognizable to youth audiences and specifically encourages youth participation. Such placements occur in both 21 Jump Street (Lord, Miller 2012) and Mean Girls (Waters 2004). Perhaps just as importantly, the subject matter of the productions is not remotely political: both are comedies set in high schools. Viewers are more likely to be young, but not more likely to be politically aware than the average population or predisposed to certain political leanings. 

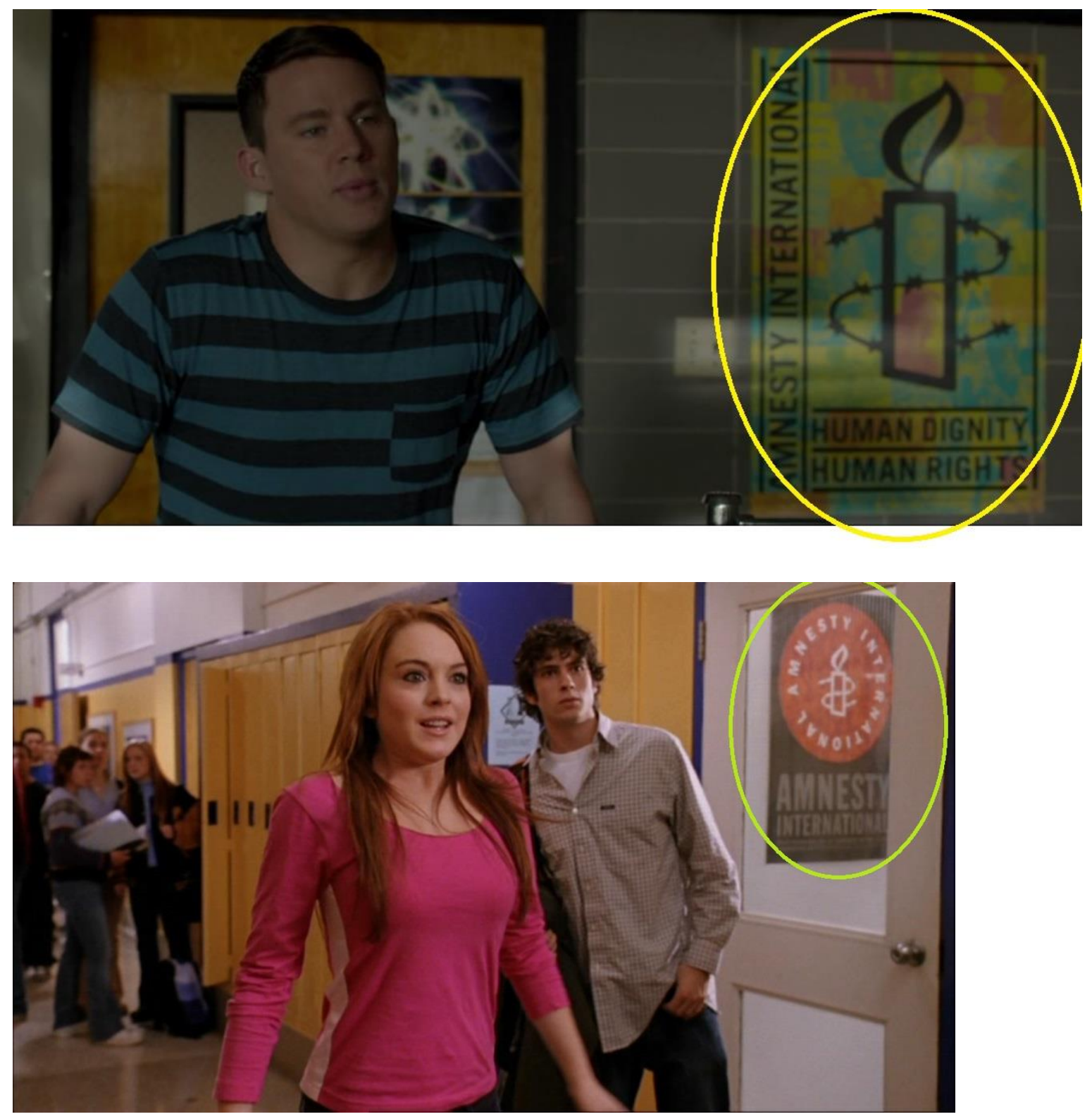

Figure 4 and 5: 21 Jump Street (2012) and Mean Girls (2004)

Seeing an Amnesty poster in a high school setting, then, offers an example of youth-oriented human rights activism as a normal activity, like any other after-school club. Amnesty International sections in high schools are relatively common; in 2013 there were over 1,000 registered youth and high school Amnesty USA groups, and the organization offers a starter kit as well as numerous communication tools and activity guides for young people (Amnesty International nd). Seeing one on film might just inspire a student to create one herself. 


\section{b) Costume}

The first poster discussed above, in Toby Ziegler's office, helps inform his character, since presumably the character would have chosen his own office decorations. But set dressing is not the only way to inform character: sometimes the most direct route is by dressing the actor himself.

Two television doctors on two different shows have sported Amnesty International T-shirts. The two doctors are John Carter of ER, played by Noah Wyle, and Christopher Turk on Scrubs, played by Donald Faison. The effect on the viewer of seeing these two characters wearing Amnesty t-shirts is different due to the amount of knowledge viewers already have of these characters' political beliefs.

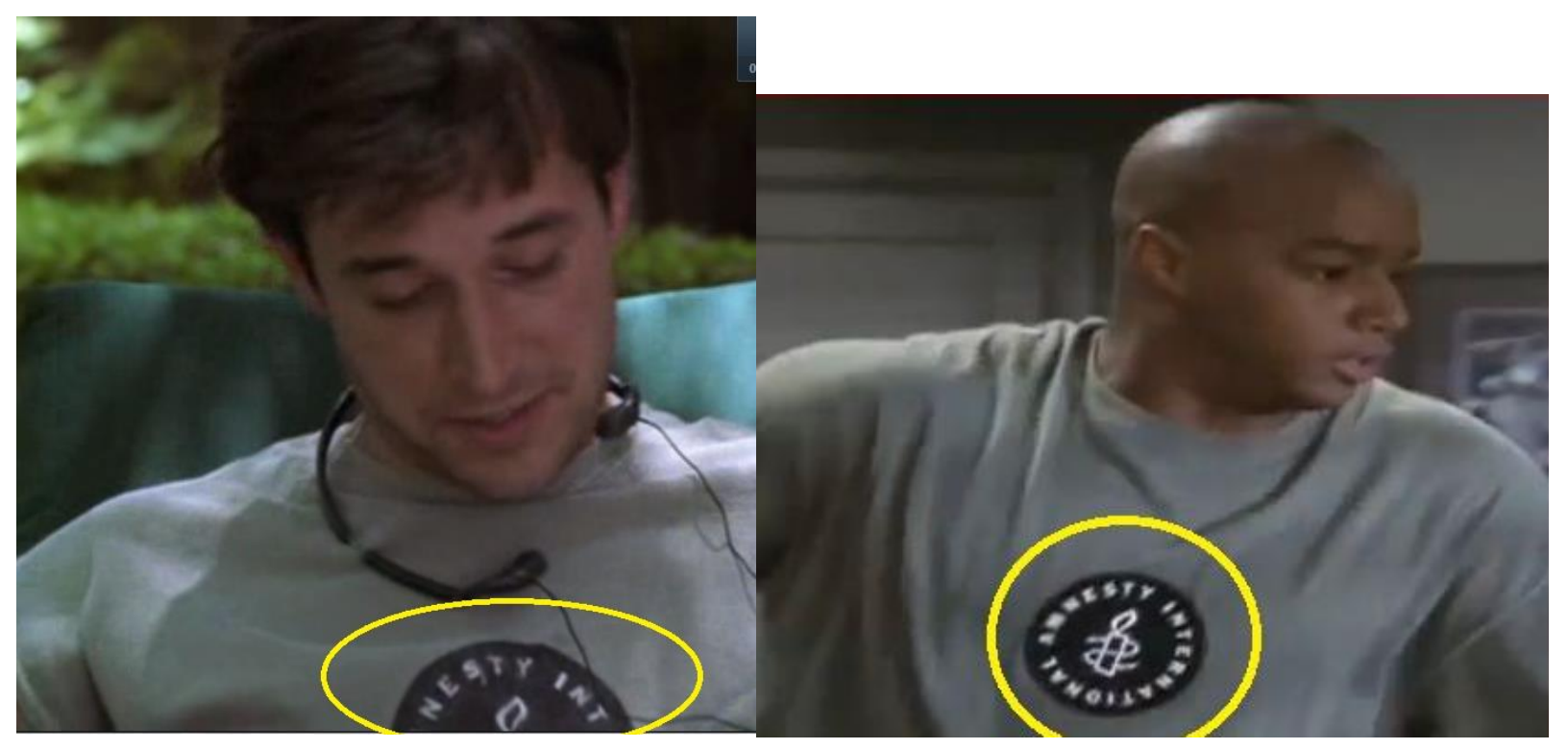

Figure 6 and 7: ER (2002) and Scrubs (2002)

The medical drama $E R$ did not shy away from political, international, or human rights issues over its 15 -year run, and the character of Dr. Carter was particularly engaged in these topics within the show environment. In 2001, Dr. Carter wore an Amnesty International t-shirt (Thorpe 2001). Although wearing the shirt was the actor's choice out of a number of other wardrobe choices, and although Amnesty would have had the shirt onscreen on an extra if actor Noah Wyle had not chosen it (Calvo 2002), in this case an 
Amnesty logo literally being worn by a character helps inform the viewer of that character's personal beliefs by tying him to a real-world organization which mirrors those beliefs. That Dr. Carter would be an Amnesty supporter is not surprising: this placement does not necessarily add anything to the plot or character development of Dr. Carter, nor does it surprise viewers that he would be wearing such a t-shirt. In an expected environment, on what many believe is the stereotypical Amnesty International supporter, this placement is basically just for brand recognition.

Dr. Turk, on the other hand, is a political unknown - until he wears an Amnesty shirt (Trilling 2002). Scrubs was a half-hour comedy set in a hospital, and rarely discussed political issues. If previous studies on non-political placements are correct, the incongruous nature of the placement might actually lead to a negative perception of the product (Couldry, Markham 2007). However, since this placement is on a character, it also informs character development: when an apolitical character on an apolitical show appears onscreen in a political t-shirt, viewers are presented with an anomaly and learn something about that character that they did not already expect. They could potentially discount it. However, might they instead learn something else: if people can be politically aware and active without it being overtly apparent, even if you know someone fairly well (as the audience believes it knows Turk), perhaps the people in the viewer's everyday life are more politically active than originally thought. Such activity - in this case, through Amnesty International - becomes more 'normal.'

\section{Auditory: 'About a Boy' vs. 'Slumdog Millionaire'}

The context in which Amnesty is referred to with an auditory placement, complete with differences in tone, has a potential effect on how viewers perceive the organization: is it to be taken seriously or not? Is Amnesty's earnestness to be praised and emulated or smiled at indulgently? Two examples of auditory placements help to illuminate this dilemma: the romantic comedy About a Boy and Mumbai-based drama Slumdog Millionaire. 
About a Boy (Weitz, Weitz 2002) is a romantic comedy revolving around the relationship between a man and the son of the woman he is attempting to date. The male lead, Will (Hugh Grant), is initially presented as immature, shallow and cynical. It is he who mentions Amnesty International:

That's the problem with charity. You must mean it.

You have to mean things to help people.

Like the time I volunteered to help out at a soup kitchen...

....and very nearly made it.

Or the time at Amnesty International.

...Wait a minute. You say you haven't got a boyfriend? Talk about a human rights violation.

In this context, Amnesty is presented as an ideal: only 'good,' earnest people engage with it, but many if not most of us aren't passionate enough about the subject to really get involved. To add insult to injury, only moments later Will, in an attempt to be witty, actually trivializes the core of Amnesty's work by comparing being single to having one's human rights violated. Such a placement, while probably leading to name recognition for viewers, creates the impression that Amnesty International is perhaps too serious for its own good.

In Danny Boyle's Oscar-winning film Slumdog Millionaire (Boyle 2008), the viewer also hears mention of Amnesty: this time by a police inspector (Irrfan Khan) worried about the exposure of torture:

INSPECTOR OF POLICE: He's unconscious, chutiya. What good is that? How many times have I told you-?

SERGEANT SRINIVAS: Sorry, Sir.

(The door opens and a Constable walks in)

CONSTABLE: The Englishman is here, Sir.

(The Inspector turns to Sergeant Srinivas with heavy irony)

INSPECTOR: Aré wa, Srinivas! Now, we'll have Amnesty International in here peeing their pants about human rights. Get him down for God's sake and clean him up.

In this case, although the character himself is dismissive of Amnesty, the viewers have just witnessed someone being tortured onscreen. The police inspector is the 'bad guy' in this situation, and his rejection of Amnesty may create a positive impression for viewers of both the organization and its effectiveness. Its use here, within the story, actually serves the purpose Amnesty International wishes to serve in the real world: ending human rights abuses. 


\section{Plot Integration: Lord of War and Blood Diamond}

The most intense insertion of $\mathrm{AI}$ and human rights issues into popular media comes in the form of plot integration. In this case, the story told uses a major human rights issue as its backdrop, and writers and producers have worked with Amnesty International and other human rights NGOs to make sure that their information is as accurate as it can be in a fictional piece. A form of edutainment rather than simple brand recognition or association, I suggest that this affords the opportunity for issue-specific advocacy and to call upon all four of Keck and Sikkink's (1998) advocacy tactics: information politics, symbolic politics, leverage politics, and accountability politics.

Information politics present viewers with facts and other usable information which they did not have and which might cause a change in belief or behavior. Symbolic politics uses symbols (such as logos), persons, or stories to help audiences both make sense of a situation and become sensitized to the moral issue at hand. Leverage politics involves using those who have power, and can thus effect change, to help those who do not and cannot. Lastly, accountability politics attempts to hold powerful actors to the promises they have made about their actions. All four tactics, in combination, are routinely used in human rights activism over a variety of media and non-media platforms (Keck, Sikkink 1998, Thrall, Stekula et al. 2014, Isaacs 2003, Vestergaard 2008, Ron, Ramos et al. 2005).

The 2005 film Lord of War (Niccol 2005) brought light and dramatic flair to the issue of illicit global arms sales. The main character is Yuri Orlov (Nicolas Cage), an arms dealer who gains and loses fortune, power and family over the course of his life and career. What the viewer also sees is the nature and workings of the global arms trade, and the harms it produces. One is presented with relevant information and a symbolic frame within which to understand its importance: 'nine out of ten war victims today are killed with assault rifles and small arms...that's the real weapon of mass destruction.' Viewers are informed and made passionate about an issue through the use of symbolic and information politics. 
But one is not presented with an option for Keck and Sikkink's third tactic, leverage politics: there is no apparent action to take to fix that statistic; no one to lean on to change the policy.

While the biggest arms dealer in the world is your boss - the President of the United States, who ships more merchandise in a day than I do in a year - sometimes it's embarrassing to have his fingerprints on the guns. Sometimes he needs a freelancer like me to supply forces he can't be seen supplying. So. You call me evil, but unfortunately for you, I'm a necessary evil (Niccol 2005).

This may be an attempt at Keck \& Sikkink's fourth tactic, accountability politics: showing there is a disconnect between discourse and practice, particularly for governments, and therefore 'shaming' them into action. However, one does not get the impression that such attempts will work. Although one might be educated on and emotionally invested in the issue presented, the storyline of the film leaves the viewer pessimistic about the chances for that issue's resolution and the ability of the average person to impact it. This person would be less likely to take concrete action (in the form of a petition or other political message) than one who thought they could actually make a difference. Rather than empowering individuals to act, the film makes a systemic problem seem impervious to citizen-based political activism. This film may actually lessen Amnesty's perceived ability to affect systemic change.

Blood Diamond (Zwick 2006), on the other hand, offers a clear way for viewers to take individual action, even if Amnesty itself is not identified in the film. Set amidst the brutal Sierra Leonean civil war in 1999, the story follows the partnership of a diamond smuggler (Leonardo DiCaprio) and a poor fisherman (Djimon Hunsou) as they journey to find a valuable diamond and a kidnapped son. They are aided by a journalist (Jennifer Connolly), whose work provides a convenient way to place facts and exposition into the script. Those facts include both a verbal mention of the NGO Global Witness and its longstanding work on conflict diamonds as well as an explanation of exactly how the conflict diamonds system works. The connection between specific information and Global Witness as the issue expert aids both the organization and the issue. In this case, although Amnesty also works on conflict diamond and has provided advice to the film's writer and producers, it is another NGO which captures the spotlight, as 
they were the authors of a report seen early in the screenwriting process which changed the trajectory of the film's development (Faye n.d.).

Although the problem is dire, the journalist sees potential for change: 'The people back home wouldn't buy a ring if they knew it cost someone else their hand. ${ }^{10 ،}$ Both a frame and a leverage point are presented. Viewers are informed about an issue, shown why it is important, and presented with an action that they, as consumers, can take: don't buy conflict diamonds. The film ends on a hopeful note, which includes an expression of successful accountability politics: the boycotting of a diamond company and the signing of the Kimberley Accord. The viewer is left informed, emotionally connected, empowered to act, and hopeful that their action will be helpful to the cause.

Neither of the above examples explicitly mentions Amnesty International; indeed, one even mentions a different organization. If Amnesty were judging the effectiveness of its product placement efforts solely on whether its name or logo showed up on screen, then its efforts failed for these two films. However, this is the key difference between non-profit and for-product placement: whereas the corporation's goal is to attract consumers to its brand, AI has a secondary goal: to create awareness of specific human rights issues and potentially spur action to confront them. Amnesty International's USA section offered expert commentary to the media and created educational materials to coincide with the release of each film, generating numerous opportunities for a newly interested public to engage with both the topic and the organization. In addition the DVD edition of Lord of War contained a special message from star Nicolas Cage which directed viewers to Amnesty International for more information and ways to act (Amnesty International USA n.d., Niccol 2005). For both these films, the way to Amnesty was through human rights issues themselves rather than AI brand recognition.

\section{THE ETHICS OF CORPORATIZED ADVERTISING AND FICTIONAL REPRESENTATION}


In an increasingly corporatized and consumption-centered world, Amnesty International is not alone in struggling with the question of whether or not to embrace corporatized institutional structures and advocacy strategies. Dauvergne and LeBaron (2014) argue that the turn towards 'branding' is reflective of a larger shift in political activism, moving away from community- or issue-oriented groups which challenge the existing world order to movements which are centrally organized, managed from the top-down, and frequently work with and within (and thus implicitly accept and help to reproduce) the corporate order they are trying to change. They argue that political activism has largely become 'deradicalized,' and that NGO 'branding' has become a necessary tool in the search for organizational funding and visibility. Although brand management is seen as essential for the Amnesty International's financial stability, serious concerns have been expressed about 'contamination of the image' and the values associated with it. Amnesty has been reluctant to overtly embrace a language of branding and corporatized advertising strategy even though it has been engaging in it (in various forms) since the 1980s (Hopgood 2006).

This turn to brand-sensitive, corporatized operations can be seen in other aspects of NGO practice, by no means unique to Amnesty, such as website design, the use of celebrity advocates, and partnerships with corporate sponsors to sell ethically branded goods. I argue that it is far from clear, however, that this is necessarily a bad thing. If the use of successful advertising techniques enables NGOs to do better issue-oriented work, they should be seen as enabling, as well as limiting, the scope of possible political action. If new participants are sensitized to issues and given ways to participate in human rights processes, either politically or economically, such campaigns may be more immediately effective than campaigns which depend on long-term engagement from strongly committed activists. Furthermore, if involvement in a campaign through weak social ties (such as engaging in the popular culture) leads some of these individuals to maintain and deepen their ties to human rights organizations, then spreading a 'culture' of human rights through superficial outlets may lead to an increase in long-term committed human rights activists who have fully internalized the human rights message. Whether this actually 
happens, and whether the concern of de-radicalization and the benefit of increased cultural relevancy balance out in terms of improvements in global human rights practices, is unclear.

Another ethical question involves the accusation of 'commodity activism,' in which campaigns are targeted at the identity of the campaigner rather than the needs of the victims. By shifting the focus from those who need it most to those who are likely to consume the media in question, commodity activism removes agency from the beneficiaries of human rights policies, who need it most, and gives it to the activists themselves. It also risks trivializing the very real and very dangerous work that human rights defenders do around the world by linking activism with entertainment. Additionally, by making human rights activism 'cool' rather than 'necessary,' this type of marketing strategy 'risks reinforcing the public's skeptical consumerism towards human rights appeals as well as their moral apathy towards distant suffering (Waldorf 2012).'

On the other hand, the use of fiction as a method of relaying information and creating affect has some potential advantages, especially as regards risk to human rights defenders on the ground. By dramatizing, rather than directly relaying, stories of oppression, fiction can help to preserve the anonymity and safety of sources. Although Amnesty and other groups take much care to protect their networks of informants, it is an ongoing struggle to make sure that the detail presented in reports does not reveal informants' identities and make them, or their families and villages, targets. In addition, by amalgamating multiple experiences and making connections between processes and victims of oppression, a single fictional story may also impart more information than a single real story. Lastly, it is of course in the interests of the filmmakers to tell a story in such a way that it makes profits, but the goals of clear conveyance of information, the production of affect, and a profitable final product are not necessarily opposed. A well-told story that produces an emotional response is also one which is more likely to garner positive reviews and increased viewership, exposing more people to human rights stories and the embedded names and logos contained within them. 
As regards the specific ethics of embedded advertising, another ethical problem arises. The very act of product placement involves a certain amount of purposeful deception. The intent is to sink messages 'subconsciously,' so that the consumer may not even be aware that a product is being marketed at her. For organizations which praise and generally practice transparency unless it would endanger those on the ground, the use of potentially deceptive practices may cross ethical boundaries. Tellingly, this particular advertising strategy is not mentioned anywhere on AIUSA's website. Rather than calling visitors' attention to some of the more overt forms of cultural marketing such as tribute CDs, film festivals and rock concerts, AIUSA neither publicly celebrates nor even mentions its successful product placements. Hackley et. al. (2008) suggest that some of the ethical murkiness surrounding embedded advertising may be alleviated by making such strategies more explicit, such as publicizing the fact that such placements are pursued. However, such overt identification of strategy may create other problems: in one study on stealth advertising, the knowledge that a company engaged in such efforts diminished participants' brand loyalty, but this effect was moderated somewhat depending on brand familiarity and the sense that the marketing tactic was "appropriate" (Wei, Fischer et al. 2008).

These ethical considerations about Amnesty International's media strategy have been the subject of a certain amount of disagreement between the International Secretariat and AIUSA, which is both AI's largest national section and the instigator of most product placements (Hopgood 2006, 136-142). Other national sections have not used product placement to the extent that AIUSA has, although this may also be related to the different rules surrounding the practice in different countries. On the other hand, this difference in preferences on media advocacy strategies is also similar to research demonstrating differences in the relative acceptance of corporatized marketing, particularly within the arts, between American and other global entertainment consumers (Gould 2000, Sung, Lee 2011, Slim Khalbous, Donata Vianelli et al. 2013). This suggests that AIUSA may be the most enthusiastic about the use of product placement because Americans in general are the most receptive to it. 
American audiences are also the largest financial contributors to AI's operations. Although AI strives to be a global, multicultural human rights organization, the vast majority of its funding comes from rich Western states. The International Secretariat receives nearly $25 \%$ of its funding from the US section alone (Hopgood 2006, 197). Financial stability and growth are dependent on states for which entertainment-based advertising is widely accepted as normal. In addition, each national section holds ownership of the Amnesty logo (the candle and barbed wire) in their own country, meaning that the Secretariat is dependent on funding from states which are particularly receptive to this form of advertising and relatively helpless to stop it without financial risk.

These ethical critiques of product placement in general, and for non-governmental organizations in particular, suggest that different organizations will come to different conclusions regarding their own entry into the field of product placement. For many organizations, the decision may ultimately rest on the perceived need to 'not be left behind' in the fight for visibility and funding.

\section{CONCLUSION}

This article has presented a somewhat paradoxical human rights practice: placing brand names, logos, and issues which are serious, political and normatively important into the generally lighter, sometimes fantastical, and profit-driven world of mass entertainment. While the contradiction may seem strange to some, the human rights movement has always operated via multiple moving parts: some do dangerous in-country work, while others lobby governments and stand up for activists at risk, and still more educate and raise awareness around the world. As Keck and Sikkink (1998) argue, the work of many different actors and strategies is necessary to advance and promote human rights. Product placement, while a relatively new tool in the advocacy repertoire, deserves to be analyzed and understood not just for its novelty but for its potential to contribute positively to organizations' recruitment and outreach activities. 
Evaluating the impact of subconscious advertising on political engagement, rather than product identification and consumption, is difficult to accomplish without experimental studies or detailed viewer/participant tracking. Do viewers learn about an issue or see an Amnesty poster on a set, go to AI's website, and keep coming back? Do they sign up for a mailing list, make a financial contribution, or join a group? If they are brought to Amnesty by an issue film like Blood Diamond, does that single-issue passion lead to a greater general interest in human rights? It is hoped that this article may serve as a catalyst to future studies of political culture which engage the arts themselves.

The interplay between politics and culture is exactly what Amnesty is hoping to exploit: 'We're about building a culture of human rights... and in order for us to do that, we have to be at the epicenter of pop culture (Calvo 2002).' From specific issues and specific organizations to a general culture of rights, the potential for cultural products to influence the practice of political activism in a number of traceable or measurable ways most certainly exists, and deserves to be further explored.

AMNESTY INTERNATIONAL, nd-last update, Human Rights Friendly Schools Network: About Us . Available: http://friendlyschools.tiged.org/?about=hrfsn [02/11, 2014].

AMNESTY INTERNATIONAL, 2014-last update, Amnesty International: Who We Are. Available: http://www.amnesty.org/en/who-we-are [02/10, 2014].

AMNESTY INTERNATIONAL USA, n.d. Lord of War Education Guide.

BABIN, L.A., 1996. Advertising via the box office: Is product placement effective? Journal of Promotion Management, 3(1-2), pp. 31-52. 
BOYLE, D., 2008. Slumdog Millionaire. 2008: Fox Searchlight Pictures.

CALVO, D., 2002, January 6, 2002. Amnesty's New Cause. Los Angeles Times.

CARLSON, G.S., 2012. Channel Surfing Knowledge: A Narrative Criticism of Edutainment Television Programming, ProQuest, UMI Dissertations Publishing.

CMIEL, K., 1999. The Emergence of Human Rights Politics in the United States. Journal of American History, 86(3), pp. 1231.

COOPER, H., SCHEMBRI, S. and MILLER, D., 2010. Brand-self identity narratives in the James Bond movies. Psychology \& Marketing, 27(6), pp. 557.

COULDRY, N. and MARKHAM, T., 2007. Celebrity Culture and Public Connection: Bridge or Chasm? International Journal of Cultural Studies, 10(4), pp. 403.

DAUVERGNE, P. and LEBARON, G., 2014. Protest Inc. Cambridge: Polity Press.

FAYE, D., n.d.-last update, Diamond Scribe: Interview with Charles Leavitt [Homepage of Writers Guild of America West], [Online]. Available: http://www.wga.org/content/default.aspx?id=3136 [12/18, 2013].

FINNEMORE, M. and SIKKINK, K., 1998. International Norm Dynamics and Political Change. International Organization, 52(4), pp. 887-917.

FUJAWA, J., 2012. The FCC's Sponsorship Identification Rules: Ineffective Regulation of Embedded Advertising in Today's Media Marketplace. Federal Communications Law Journal, 64(3), pp. 550.

GLUCK, W., 2011. Friends With Benefits. USA: Screen Gems.

GOULD, S.J., 2000. Product Placements in Movies: A Cross-Cultural Analysis of Austrian, French and American Consumers' Attitudes toward This Emerging, International Promotional Medium. Journal of Advertising, 29(4), pp. 41-58.

HACKLEY, C., TIWSAKUL, R.A. and PREUSS, L., 2008. An ethical evaluation of product placement: a deceptive practice? Business Ethics: A European Review, 17(2), pp. 109-120.

HERO ENTERTAINMENT MARKETING, nd-last update, Clients [Homepage of Hero Entertainment Marketing, Inc.], [Online]. Available: http://www.heropp.com/category/client/ [02/12, 2014].

HOLBERT, R.L., O., P., D.A., T., ARMFIELD, G.G., KINDER, K., CHERRY, K.L. and ET.AL., 2003. The West Wing as Endorsement of the US Presidency: Expanding the Bounds of Priming in Political Communication. Journal of Communication, 53(3), pp. 427.

HOPGOOD, S., 2006. Keepers of the flame: understanding Amnesty International. Ithaca, N.Y: Cornell University Press. 
ISAACS, A., 2003. Like Water on Stone: The Story of Amnesty International. Common Knowledge, 9(1), pp. 166-166.

JONES, C.A., 2002. Investigating the Effectiveness of Product Placement in Television Shows: The Role of Modality and Plot Connection to Congruence on Brand and Memory Attitude. Journal of Consumer Research, 29, pp. 306.

KECK, M.E. and SIKKINK, K., 1998. Activists beyond borders: advocacy networks in international politics. Ithaca, N.Y: Cornell University Press.

KRAIN, M., 2012. J'accuse! Does Naming and Shaming Perpetrators Reduce the Severity of Genocides or Politicides? International Studies Quarterly, 56(3), pp. 574-589.

LA FERLE, C. and EDWARDS, S., 2006. Product Placement: How Brands Appear on Television. Journal of Advertising, 35(4), pp. 65.

LEHMANN, M., 1999. The West Wing: Five Votes Down. Los Angeles, CA: NBC.

LORD, P. and MILLER, C., 2012. 21 Jump Street. USA: Columbia Pictures.

NICCOL, A., 2005. Lord of War. USA: Lions Gate Films.

RAMOS, H., RON, J. and THOMS, O.N.T., 2007. Shaping the Northern Media's Human Rights Coverage, 1986-2000. Journal of Peace Research, 44(4), pp. 385-406.

RON, J., RAMOS, H. and RODGERS, K., 2005. Transnational Information Politics: NGO Human Rights Reporting, 1986-2000. International Studies Quarterly, 49(3), pp. 557-588.

SLIM KHALBOUS, DONATA VIANELLI, TOMASZ DOMANSKI, CHRISTIAN DIANOUX and MERIEM MAAZOUL, 2013. Attitudes toward Product Placement: A Cross-Cultural Analysis in Tunisia, France, Italy, and Poland. International Journal of Marketing Studies, 5(2), pp. 138.

SLOVIC, P., 2007. "If I look at the mass I will never act": Psychic numbing and genocide. Judgment and Decision Making, 2(2), pp. 79.

SUNG, Y. and LEE, T.D., 2011. Cross-cultural challenges in product placement. Marketing intelligence \& planning, 29(4), pp. 366-384.

THORPE, R., 2001. ER. USA: Warner Brothers Television; NBC.

THRALL, A.T., STEKULA, D. and SWEET, D., 2014. May We Have Your Attention Please? Human-Rights NGOs and the Problem of Global Communication. The International Journal of Press/Politics, 19(1),

TRILLING, L., 2002. Scrubs. USA: NBC.

VAN ZOONEN, L., 2007. Audience reactions to Hollywood politics. Media, Culture \& Society, 29, pp. 531. 
VESTERGAARD, A., 2008. Humanitarian branding and the media: The case of Amnesty International. John Benjamins Publishing Company.

WALDORF, L., 2012. White Noise: Hearing the Disaster. Journal of Human Rights Practice, 4(3), pp. 469-474.

WATERS, M., 2004. Mean Girls. USA: Paramount Pictures.

WEI, M., FISCHER, E. and MAIN, K.J., 2008. An Examination of the Effects of Activating Persuasion Knowledge on Consumer Response to Brands Engaging in Covert Marketing. Journal of Public Policy \& Marketing, 27(1), pp. 34.

WEITZ, C. and WEITZ, P., 2002. About a Boy. USA: Universal Pictures.

WHEDON, J., 2012. The Avengers. USA: Walt Disney Studios Motion Pictures.

YANG, M. and ROSKOS-EWOLDSEN, D.R., 2007. The Effectiveness of Brand Placements in Movies: Levels of Placements, Explicit and Implicit Memory, and Brand-Choice Behavior. Journal of Communication, , pp. 469.

ZWICK, E., 2006. Blood Diamond. USA: Warner Bros.

\footnotetext{
${ }^{2}$ The term 'edutainment' arose in the 1990s as media, software and technology developers increasingly tried to integrate educational content into entertainment products and vice versa (Carlson 2012).

${ }^{4}$ A number of studies show that product placement increases brand recognition and that viewers do not really mind seeing brands in entertainment, as long as they do not feel that their attitudes towards that brand are being directly influenced (La Ferle, Edwards 2006, Jones 2002, Yang, Roskos-Ewoldsen 2007). However, since much of the data on product placement effectiveness is proprietary, there has not been much scholarly analysis of the causal mechanisms or different success rates of different types of product placements.

${ }^{5}$ One well-known example of successful product placement is that of Reese's Pieces in the movie E.T.: The Extraterrestrial (1982). In the film, the protagonist (Elliott) uses the candies to lure ET out of the forest and into the house. Although the label on the bag is never seen, the candy's bright orange color is distinctive, and sales of Reese's Pieces reportedly increased by 65\% within a month of the film's release (Babin 1996).

${ }^{6}$ This particular competition, between Amnesty International and Human Rights Watch, has been the subject of some concern by Amnesty since the late 1990s brought HRW increased media presence (Hopgood 2006, 136-142)..

8 'Actor' here is used in the political science sense of the word, rather than the Oscars/Emmys/Golden Globes sense of the word.

${ }^{9}$ Although Friends with Benefits is not a politically-oriented film, the particular office in question is.

10 This is essentially the same frame used earlier, by Global Witness and others, in a print marketing campaign in the early 2000s. Repeating the frame might create resonance with pre-existing advocacy efforts, therefore enhancing recall.
} 